\title{
The Impact of Understaffing on Delaying Early-Stage SARS-CoV-2 Outbreak Detection
}

BOUKARI WADJIDOU ( $\nabla$ wangji18@mails.tsinghua.edu.cn )

Tsinghua University https://orcid.org/0000-0001-7011-2110

Ivana Todorovic

Tsinghua University School of Medicine

Long Fenjie

Tsinghua University

Research

Keywords: SARS-CoV-2 Understaffing risks, Dempster-Shafer Theory (DST), Evidential reasoning (ER)

Posted Date: September 10th, 2020

DOI: https://doi.org/10.21203/rs.3.rs-73592/v1

License: (c) (1) This work is licensed under a Creative Commons Attribution 4.0 International License.

Read Full License 


\title{
The impact of understaffing on delaying early-stage SARS-CoV-2 outbreak detection
}

\author{
Abstract \\ Background
}

Having a minimum number of workers in medical services is widely regarded as a key component of disease prevention. However, with the delay in confirming cases of SARS$\mathrm{CoV}-2$, the understaffed medical providers informed late and the virus has rapidly spread nationally.

\section{Methods}

This study, based on the Dempster-Shafer theory method and Evidential Reasoning, assesses the risks posed by understaffing for the SARS-CoV-2 outbreak.

\section{Results}

The findings examine six (6) factor risks and show that the understaffing risk in 2019 was $0.14 \%$ in magnitude in Wuhan, compared to $0.27 \%$ in Shenzhen. When ranking understaffing risks from low to high, the findings show that they increased from 3.979 to $3.983 \%$ and from 3.998 to $4.002 \%$ in Wuhan and Shenzhen, respectively.

\section{Conclusions}

We first conclude that from the SARS-CoV-1 to the SARS-CoV-2 outbreak, understaffing risk equally increased at $0.004 \%$ in both cities. However, Shenzhen city is at a higher risk than Wuhan city. Second, Shenzhen understaffing delayed SARS-CoV-2 outbreak prevention 0.13\% more than Wuhan city. We generally conclude that Shenzhen city could be doubly worse off than Wuhan city if it was the epicenter of the SARS-CoV-2 outbreak. Therefore, public health care training and employment policy must be optimized to complete the lack not only in both cities but also in other cities to prevent future outbreaks.

Keys words

SARS-CoV-2 Understaffing risks, Dempster-Shafer Theory (DST), Evidential reasoning (ER) 


\section{Introduction}

SARS-CoV-2, which includes similar symptoms of SARS-CoV-1, was discovered in Wuhan at the end of 2019[1]. Before medical workers officially informed China's population, the World Health Organization (WHO), and the rest of the world, the disease had already spread from Hubei province to other parts of China. The delayed response in Wuhan allowed the infection to spread and death count to rise. Once Chinese authorities acknowledged the severity of the outbreak, the government began to train 35.000 medical workers, include military health workers to assist in Shenzhen and Wuhan city, the epicenter of the outbreak. Seven thousand other medical workers from (16) provinces assisted in 16 other cities and prefectures in Hubei. On March 16, Ruiyun Li. et al., [2] highlighted the importance of detecting asymptomatic SARs S-CoV-2. This outbreak is similar to 2002-2003 pandemic, where hospitals in Guangdong province were understaffed and the health care system in other cities in China was collapsing. ${ }^{1}$ Limited medical services will not protect the population. Instead, are dealing with secondary challenges such as complacency and; low morale. Therefore, it is time to learn from our mistakes so that we can improve conditions in hospitals to ensure the safety of populations in China. During the 2002 SARS-CoV-1 outbreak, people experienced similar symptoms, including fever, cough, and respiratory[3,4]. It is not surprising that there are similar challenges with SARS-CoV-2, as there were in 2002. Now as then, understaffed medical facilities continue to be a crutch to the healthcare system in the majority of Chinese cities. With schools, universities, childcare centers, supermarkets, stadiums, and other places for mass gathering closed, many of China's cities became ghost towns. And, the population relies on the hard work of health workers to cure the virus and allow them to return to normal life.

This study following philosophy who states that[5]:

There is no longer the feeling of being working where burnout governs human being. Under workload must be respect instead of over workload. If not, multiple errors in work and injuries or disasters occur. And, the consequences are considerable. 
Therefore, we will estimate how understaffed hospitals increase the risk of spread in Wuhan and Shenzhen by using the Dempster Shafer Theory (DST) and its Evidence Reasoning approach (ER).

Understaffing increases the risk of workplace injury

Scholars highlighted the fact that the lack of staff at work leads to incapacity of doctors or other workers in the hospitals. ${ }^{5}$ However, not having enough people on duty can be hazardous in a variety of public hospitals and clinics [6]. Employee does gets rewards for overloaded work. In case the rewards monetary may not satisfy the requirement of workers, work conflicts could also rise[7]. All these working conditions put workers into psychological problems and then potential disasters are no longer well controlled by workers in services, which in turn could cause injuries[8]. As an example, the decrease in disease prevention is observed in Iraq while understaffing is sustained, with population and immigration growing up [9]. Especially, in SARS-CoV-1, 40\% of understaffing was not able to prevent disease [10]. On the other hand, understaffing leads to certain health workers fear-driven absenteeism [11], patients health workers virus transmission [12,13,14], and succumbing of staff during their duty [15]. Additionally, medication errors occurred in hospitals are mainly caused by lack of personnel, which is associated with inadequate patient supervision and no regularly reporting of daily patients medical $[16,17,18]$. Sometimes, public health workers require additional hands from hospitals and clinics which experience high inpatient and outpatient visits to avoid risk of injury and illness [19]. Having enough people to perform tasks helps prevent long-term illness among workers as well as any immediate hazards or disasters, which in turn may help employers drive productivity and increase revenue[20].

Understaffing may result in accidents

Inadequate staffing can become a liability for employers if it continues over a long period of period. Recent research published in the Journal of Advanced Nursing (JAN) found an increased workload and a decrease in ability to perform among nurses related to accidental organ failure [21]. Reducing the number of employees to the lowest level of facility negative outcome [22]. As example, twenty-six (26) countries affected by SARS-CoV-1 epidemic have 
experienced undernumbered medical staff. Besides, a small number of cases have occurred as a result of laboratory accidents in Guangdong [23]. SARS-CoV-2 outbreak has caused accidents among health workers during their work time because of lack of physicians in the USA [24]. Additionally, human error is inevitable in medicine, especially in health care crises where understaffing is high remarked and both patients and physicians receive shocks $[25,26,27]$. Moreover, Worldwide health care disaster costs 20 to $-40 \%$ of the budget due to understaffing and physician errors on patients [28]. Lack of personnel is the cause of unsafety or nonrespected desire of patients by nurses. Which was reflected by the case of missing nursing care or omission errors in Saudi Arabic public hospitals [29]. Long-term understaffing increases errors, omissions, or damages and has negatively impacted workers health [31,32]. Lapses in following industry regulations or proper safety precautions around machinery are some of the issues that can arise from overworked employees. Many times, in these situations, occupational fatigue leads to disengagement and decreased productivity [33].

Stress leads to turnover

Increased levels of stress associated with insufficient staffing levels can negatively impact employee health and may even cause worker turnover, leading to more issues for employers[34]. And, putting patients at high risk of succumbing to virus transmission or negative tests [35]. Additionally, both SARS-CoV-1 and Middle East Respiratory Syndrome (MERS) outbreaks were experimented under high understaffing as a result of stress burnout among workers [36,37]. Moreover, depression and psychophysiological symptoms among health workers [38].

impact negatively on occupational health and mental states [40,41].

A study from SARS-CoV-2 outbreak found Nurses who reported elevated stress levels faced by infected and infecting other [5]. Thus, infected and other health-related issues can impair worker productivity and can boost the number of sick days. Employers may also see increases in healthcare insurance costs if workers are sick more often. Employees who work excessively may also seek out other job opportunities, leaving employers with the timeconsuming and costly task of hiring and training new staff[42,43]. On the order of words, overstress gives also employees the intention to quit their jobs and seek for alternative work which may better enjoy their standard life $[44,45,46,47]$. Understaffing associated with stress has a long run repercussion for health care, including poor working conditions or encouraging 
errors to be overlooked[48]. Therefore, employers may easily make error in disease prevention (HIV/AIDS, influenza, MERS, SARS-CoV), or may require additional workers to assist. Healthy worker is the first condition to prevent disease and reduce staff injury and illness [49], and not having enough workers leads to less productivity and other uncertainty issues in work contract $[48,49,50]$.

\section{Dempster-Shafer And Evidential reasoning theories}

The Dempster-Shafer Theory of Evidence (DST) treats imprecise, uncertainty and incomplete information [51,52]. And, to provide its consistency, DST has two functions: "belief” (Bel) and "plausibility" (Pla), both derived from the "mass function" (m). Their roles are to range weights value on behalf of DST in lower (Bel) and upper (Pla) bounds of probability risk. Mass function(m), also known as a basic probability assignment (BPA) function, is the power set of the frame of discernment $\Theta$. Generally, its formula is written with its two (2) consistency conditions:

"Mass function (m) or basic probability assignment (BPA)" (Shafer, 1976):

$$
m: P(\Theta) \rightarrow[0,1] \quad \text { With } m(\phi)=0 ; \text { and } \sum m(A)=1
$$

\section{-Condition 1 and 2}

-Belief function (Bel) is defined as:

$$
\operatorname{bel}(A)=\text { Lower risk assessment }=\sum_{B \subseteq A} m(B)
$$

-And the plausibility function (Pla) is defined as:

$$
(P l a)=\text { Upper risk assessment }=\sum_{B \cap A \neq \emptyset} m(B)
$$

“Dempster's combination rule"

In case we have multiple risk subsets of $\Theta$, the overall assessment of belief level $(\beta \mathrm{n})$ on each assessment grade, and its aggregated degree of ignorance formulas are written below. Additionally, these estimations are also supported by Evidential Reasoning (ER)[53,54]. (ER) is known as a decision-making methodology based on distributed assessments with $\mathrm{n}$ grades. And, its role is to estimate individual risk based on available shreds of evidence from DST. 
The formula of ER is $S\left(R_{j}\left(h_{i}\right)\right)=\left\{\left(G n, \beta_{n, i, j}\right), n=1, \ldots N\right\}, \sum_{i=1}^{N} \beta_{n, i, j} \leq 1$. Where $G n$ is the assessment grade $\mathrm{n}$ and $\beta_{n, i, j}$ is the degree of belief that the likelihood of occurrence of risk $R_{j}$ equals the grade $G n$. With the overall assessment aggregation $\beta_{n}$ :

$$
\beta_{n}=k\left[\prod_{i=1}^{m}\left(\omega_{i} \beta_{i, n}+1-\omega_{i}\right)-\prod_{i=1}^{m}\left(1-\omega_{i}\right)\right]
$$

Where $\mathrm{k}$ is:

$$
k=\left[\sum_{n=1}^{N} \prod_{i=1}^{m}\left(\omega_{i} \beta_{i, n}+1-\omega_{i}\right)-N \prod_{i=1}^{m}\left(1-\omega_{i}\right)\right]^{-1}
$$

And, aggregated degree of ignorance is defined as:

$\beta_{H}=1-\sum_{i=1}^{N} \beta_{n}$ and, $\sum_{n=1}^{N} \beta_{n}+\beta_{H}=1$

\section{Data sets}

Except population resident's data which are from both city statistical yearbooks, EPS (Easy Professional Superior), in China allows us to collect the majority of data sets. And table 1 shows the descriptive statistics. Moreover, the explanation of each variable is detailed as follows:

Decrease in capability of potential hazards detection

It explains how understaffed may be unaware of disasters in the workplace that doctors have been controlling. Firstly, to know the number of health workers (doctors in disease prevention and control) who take care of population, we divide the yearly population of residents by the number of assistant doctors and doctors. We then estimate the difference in number of (assistant) doctors between 2003 and each year of disease treatment. This difference is considered probability risk when the value is positive. And, there is no probability risk and the values take zero (0) when the difference is negative or zero. Then, we use percentiles to quantify doctor's ability in disease detection and prevention so that we discern a clear knowledge of hazards exposition risk in Wuhan and Shenzhen cities, respectively.

Lack of task performance or increased disease mortality rate 
Worker's inefficacity may occur when the mortality rate among patients of disease outbreak increases each year. Based on the data used in this study, we observed since the outbreak of SARS-CoV-1 in Shenzhen to SARS-CoV-2 in Wuhan, the department of disease prevention and control has experienced an increase in mortality rate. As documented by scholars[3,4], SARS-CoV-2 symptoms include sneezing, coughing, and/or fever. Which are similar to those of the SARS-CoV-1. Therefore, this factor risk shows how public health workers (doctors in charge of disease prevention and control), which are understaffed, simply got confused at the early stage of SARS-CoV-2. The lack of task performance was estimated by calculating the differences between yearly mortality due to disease and that of the reference year 2003. Which represents the year of SARS-CoV-1 outbreak. After the pandemic, the mortality rate due to disease may increase or decrease in the following years depending on depends on the performance of both doctors and assistant doctors. Therefore, doctor's tasks are accomplished successfully, there is no risk when the mortality rate decreases in the aftermath of the outbreak, otherwise, the growth rate of mortality is accounted by understaffed doctor's performance.

\section{Work overload (under stress)}

High visited patients in the hospital are natural. However, when the hospitals or centers are understaffed, workers become stressed. Stress affects negative workers through "rustout" [55]. The number of both doctors and assistant doctors in charge of disease prevention and control is inadequate in both cities' epicenter (SARS-CoV-2 Outbreak). This leads to error of early disease detection from patients. ${ }^{55}$ Therefore, work overload is the main cause of many jobrelated attitudes, i.e., stress, anxiety, resulting in poor performance and job dissatisfaction [55]. In Wuhan and Shenzhen city, the daily number of visits and inpatients per doctor (person) increased continuously from SARS-CoV-1 to SARS-CoV-2, while the number of doctors and assistant doctors in charge of disease prevention and control is decreased. It has already been proved that SARS-CoV-1 outbreak was understaffed [37,38]. Therefore, we weight overload work by estimating the differences between the daily number of visits and inpatients per doctor (person) in 2003 and the following years. The difference is considered a probability risk when the value is positive and otherwise it takes the value zero (0). Then, we use percentiles to quantify the risk probability. 


\section{Excessive workload (over stress or burnout)}

Prolonged exposure to stress often directly harms workers and indirectly impacts the outcomes. Explained excessive workload as "burnout" or a managerial inability to deal with tasks $[55,56,57]$. This has severe repercussions especially in the medical field, where an error can cause the death of thousands or over people. For example, feeling a little stressed about a high patient visit to the hospital can motivate doctors to focus when the hospital is understaffed. However, becoming exhausted can make it hard to concentrate on the tasks and determine what to do first. Therefore, doctors lose their full personal ability to complete their tasks. Thus, we quantify excessive workload by multiplying overload work risk each year by two (2).

\section{Long working hours}

It is of no surprise to observe that the number of working hours per day increased, as majority of China's city hospitals are understaffed. Additionally, a shortage of staffs reduces breaks for available workers and leads to errors in disease prevention and control. Long working hours are one of the factors risks which caused doctors to delay to inform the population on SARS$\mathrm{CoV}-2$ at the early stage. However, in both Wuhan and Shenzhen cities, the minimum work hours in the data used in this study found to be continuously increasing from year to year. And negatively impact doctors. The differences between the reference year 2003 and the following years are taken as the probability of risk of hours worked and quantified in percentage.

\section{Delay or reduction of multicomponent interventions}

Highlighted the importance that communication holds at work[58]. The risks of communication problems, written and oral, are the negative outcome of work done. To avoid this to happen, a few recommendations are broad-based and may include [37,38,55,56,57,58]: -Risk assessment includes minimizing the risk of infection transmission in hospitals to avoid patient-to-personals transmission or personals to patient transmission.

-Health education may include public health care activities like training to acquire more skills in infection detection and treatment among institutions and health care personals; Finally, technical consulting and policy proposals to better prevent and control the disease. 
-The risk of exposition hazards may have been avoided in Wuhan market if there were enough workers and regular meetings among workers and if health care institutions ensure communication about the optimized disease policy prevention.

However, data used in this study shows that, from SARS-CoV-1 to SARS-CoV-2 outbreak, the multicomponent interventions in both Wuhan and Shenzhen cities decreased. Thus, the differences between 2003 multicomponent interventions hours and the following years are considered at risk in health care sector. The magnitude of probability risks is expressed at percentage.

\section{Results}

One may argue that dealing with public health care employment assessment as a DST-ER problem is a risk mitigation and improving the ways in which understaffed risk is understood, assessed, and responded to in hospitals or clinics. Such an approach is very convenient especially in the case of analyzing employment, strategic and policies where authorities have different interests (poverty reduction and economic development) and objectives (health care system efficiency, and population well-being). DST-ER approaches for employment evaluation can assess risk in complicated situations such as pandemic period. Thus, the DST and the ER algorithm are innovatively employed to provide a successful risk assessment process. We model risk as the likelihood of occurrence and probability of impact materialization with the degrees of belief in the distributed assessments of understaffed risk impact on the disease prevention. Therefore, the distributed assessment of the impact of understaffing risk " $R_{j}$ " on disease prevention " $h_{j}$ " is obtained in the following form:

$S\left(R_{j}\left(h_{i}\right)\right)=\left\{\left(G n, \beta_{n, i, j}\right), n=1, \ldots N\right\}$, with $\beta_{n, i, j}=L * I * P$.

Where L equals to likelihood of occurrence; I an impact risk and P is the probability of impact materialization. Which implies that:

$$
\begin{aligned}
S\left(R_{1}\left(h_{i}\right)\right)= & \left\{\left(G_{2003}, \beta_{2003}\right),\left(G_{2004}, \beta_{2004}\right),\left(G_{2005}, \beta_{2005}\right),\left(G_{2006}, \beta_{2006}\right),\left(G_{2007}, \beta_{2007}\right),\right. \\
& \left(G_{2008}, \beta_{2008}\right),\left(G_{2009}, \beta_{2009}\right),\left(G_{2010}, \beta_{2010}\right),\left(G_{2011}, \beta_{2011}\right),\left(G_{2012}, \beta_{2012}\right),\left(G_{2013}, \beta_{2013}\right), \\
& \left.\left(G_{2014}, \beta_{2014}\right),\left(G_{2015}, \beta_{2015}\right),\left(G_{2016}, \beta_{2016}\right),\left(G_{2017}, \beta_{2017}\right),\left(G_{2018}, \beta_{2018}\right)\right\}
\end{aligned}
$$




$$
\begin{aligned}
& S\left(R_{6}\left(h_{i}\right)\right) \\
& =\left\{\left(G_{2003^{\prime}}, \beta_{2003^{\prime}}\right),\left(G_{2004^{\prime}}, \beta_{2004^{\prime}}\right),\left(G_{2005^{\prime}}, \beta_{2005^{\prime}}\right),\left(G_{2006^{\prime}}, \beta_{2006^{\prime}}\right),\left(G_{2007^{\prime}}, \beta_{2007^{\prime}}\right)\right. \text {, } \\
& \left(G_{2008^{\prime}}, \beta_{2008^{\prime}}\right),\left(G_{2009^{\prime}}, \beta_{2009^{\prime}}\right),\left(G_{2010^{\prime}}, \beta_{2010^{\prime}}\right),\left(G_{2011^{\prime}}, \beta_{2011^{\prime}}\right),\left(G_{2012^{\prime}}, \beta_{2012^{\prime}}\right),\left(G_{2013^{\prime}}, \beta_{2013^{\prime}}\right) \\
& \left.\left(G_{2014^{\prime}}, \beta_{2014^{\prime}}\right),\left(G_{2015^{\prime}}, \beta_{2015^{\prime}}\right),\left(G_{2016^{\prime}}, \beta_{2016^{\prime}}\right),\left(G_{2017^{\prime}}, \beta_{2017^{\prime}}\right),\left(G_{2018^{\prime}}, \beta_{2018^{\prime}}\right)\right\}
\end{aligned}
$$

The tables 2 and 3 recapitulate the risk assessments in distributed forms of $S\left(R_{j}\left(h_{i}\right)\right)$ disease prevention and control. Based on data sets, we found and affirm that, from the period during SARS-CoV-1 to SARS-CoV-2 outbreaks, the number of annual doctors in charge of disease control was on a decrease while the mortality rate kept increasing. Moreover, doctors were exposed to high work pressure due to the need for disease treatment, which also leads to a constant increase in working hours year by year. To sum up, each of these (6) factors used has 0.1666 of their likelihood of occurrence on disease prevention and we have the sum of mass equals to 1 according to DST rules. Additionally, we choose $4 \%$ of magnitude grades to assess these factor risks. To be more explicit, understaffed risk level is assessed on disease prevention using assessment grade, $4 \%$ of year to year understaffed. This means that understaffed risk $R_{j}$ has a maximum magnitude impact of $100 \%$ on disease prevention and control and their probability of impact materialization in each year direct equal to 1 of disease control and prevention [51,59]. The probability of impact materialization represents the probability that the actual risk impact equalizes the expected disaster (I) and its value is between 0 and 1. However, we choose the value one (1) for each year of risk impact effected as the data set is based on reality rather than experience. Therefore, we calculate the risk level by multiplying likelihoods of occurrence with risk impact and probability of impact materialization with the degree of belief. The findings are descripted in table 2 and 3. In each table, after estimating the distribution of risks from 2003-2018, we aggregate the individual risk assessment. Aggregating individual risk assessments allows to get different risk levels at differents years of disease prevention [59]. Moreover, it allows to get overall assessment of risk on disease prevention. Therefore, the aggregated degrees of ignorance are evaluated, and they allow to assess risk in minimum and maximum boundaries [59]. Thus, individual risk assessment aggregated, the minimum, maximum, and average risks assessment in both cities 
can be seen in tables 2 and 3, respectively. Moreover, the estimation details could also be seen. We express risk as percentage according to DST Theory role. Moreover, the assessment grade in 2003 is used to measure the belief in the expected risk of effects not materializing and materializing. The results are also shown in tables 2 and 3 and figure 1 shows the lower, upper, and average risk assessment in this study.

From these results, what we learn is that Wuhan SARS-CoV-2 outbreak was understaffed at $0.014 \%$ of magnitude, while Shenzhen city registered a higher level of understaffed with about $0.027 \%$ of magnitude. 


\section{Table 1: Description statistics}

\begin{tabular}{|c|c|c|c|c|c|}
\hline Variables & Year Obs & Mean & Std. Dev. & Min & Max \\
\hline \multicolumn{6}{|l|}{ Wuhan City } \\
\hline Wuhan Resident population (10000 person) & 18 & 951.8806 & 100.7138 & 813.8 & 1108.1 \\
\hline Total (assistant) Licensed doctors in disease control (person) & 18 & 588.9907 & 69.22097 & 423 & 681 \\
\hline Disease control, Doctors per population & 18 & 0.6309347 & 0.1279726 & 0.392896 & 0.782138 \\
\hline Daily Number of Visits and Inpatients per doctor (person) & 18 & 12.62222 & 0.972296 & 11.3 & 15.2 \\
\hline Disease mortality rate $\%$ & 18 & 0.2890422 & 0.0267252 & 0.251 & 0.3491 \\
\hline Daily multicomponent interventions(hours) & 18 & 2.105629 & 1.156741 & 0.561644 & 4.210959 \\
\hline Minimum Long working (hours) & 18 & 5.215179 & 0.5897628 & 4.289286 & 6.03 \\
\hline \multicolumn{6}{|l|}{ Shenzhen city } \\
\hline Shenzhen Resident population (10000 person) & 18 & 987.4683 & 173.1544 & 724.57 & 1302.66 \\
\hline Total (assistant) Licensed doctors in disease control (person) & 18 & 3044.176 & 394.8986 & 2457 & 3673 \\
\hline Disease control, Doctors per population & 18 & 3.11509 & 0.2823767 & 2.819615 & 3.890353 \\
\hline Daily Number of Visits and Inpatients per doctor (person) & 18 & 12.95608 & 1.222728 & 10.6 & 14.94405 \\
\hline Disease mortality rate $\%$ & 18 & 0.3565117 & 0.0741264 & 0.28 & 0.5666 \\
\hline Daily multicomponent interventions(hours) & 18 & 6.094512 & 4.065885 & 0.838356 & 12.15919 \\
\hline Minimum Long working (hours) & 18 & 6.666786 & 0.5643885 & 5.774286 & 7.49 \\
\hline
\end{tabular}


Table 2: Risk assessment in distributed forms

\begin{tabular}{|c|c|c|c|c|c|c|c|c|c|c|c|c|c|c|c|c|c|c|}
\hline Wuhan & \multicolumn{16}{|c|}{ Risk impacts(I) } & \multirow{2}{*}{$\begin{array}{c}\begin{array}{c}\text { No } \\
\text { risk } \\
\text { impact }\end{array} \\
2003- \\
2018\end{array}$} & \multirow[t]{2}{*}{ Sum } \\
\hline $\begin{array}{c}\text { Top } \\
\text { risks }\end{array}$ & 2003 & 2004 & 2005 & 2006 & 2007 & 2008 & 2009 & 2010 & 2011 & 2012 & 2013 & 2014 & 2015 & 2016 & 2017 & 2018 & & \\
\hline R1 & 0.036 & 0.037 & 0.037 & 0.039 & 0.038 & 0.041 & 0.035 & 0.051 & 0.052 & 0.051 & 0.051 & 0.051 & 0.049 & 0.059 & 0.058 & 0.055 & 0.260 & 1 \\
\hline $\mathbf{R 2}$ & 0.002 & 0.004 & 0.005 & 0.006 & 0.007 & 0.008 & 0.002 & 0.000 & 0.000 & 0.000 & 0.022 & 0.022 & 0.021 & 0.017 & 0.015 & 0.021 & 0.846 & 1 \\
\hline $\mathbf{R 3}$ & 0.1 & 0.004 & 0.006 & 0.008 & 0.01 & 0.012 & 0.014 & 0.016 & 0.018 & 0.022 & 0.02 & 0.036 & 0 & 0.007 & 0.009 & 0.005 & 0.713 & 1 \\
\hline R4 & 0.2 & 0.008 & 0.012 & 0.016 & 0.02 & 0.024 & 0.028 & 0.032 & 0.036 & 0.044 & 0.04 & 0.072 & 0 & 0.014 & 0.018 & 0.01 & 0.426 & 1 \\
\hline R5 & 0.001 & 0.002 & 0.003 & 0.004 & 0.005 & 0.007 & 0.008 & 0.009 & 0.010 & 0.009 & 0.011 & 0.015 & 0.016 & 0.016 & 0.016 & 0.015 & 0.852 & 1 \\
\hline R6 & 0.030 & 0.030 & 0.000 & 0.026 & 0.000 & 0.000 & 0.021 & 0.009 & 0.000 & 0.000 & 0.000 & 0.000 & 0.000 & 0.000 & 0.000 & 0.000 & 0.885 & 1 \\
\hline
\end{tabular}

\begin{tabular}{|c|c|c|c|c|c|c|c|c|c|c|c|c|c|c|c|c|}
\hline \multicolumn{17}{|c|}{ Distributed forms of risk level assessments: L*I*P with its degrees of belief } \\
\hline Grade & $4 \%$ & $4 \%$ & $4 \%$ & $4 \%$ & $4 \%$ & $4 \%$ & $4 \%$ & $4 \%$ & $4 \%$ & $4 \%$ & $4 \%$ & $4 \%$ & $4 \%$ & $4 \%$ & $4 \%$ & $4 \%$ \\
\hline Top risks & 2003 & 2004 & 2005 & 2006 & 2007 & 2008 & 2009 & 2010 & 2011 & 2012 & 2013 & 2014 & 2015 & 2016 & 2017 & 2018 \\
\hline R1 & 0.0241 & 0.0246 & 0.0247 & 0.0258 & 0.0250 & 0.0276 & 0.0232 & 0.0341 & 0.0344 & 0.0337 & 0.0340 & 0.0343 & 0.0330 & 0.0393 & 0.0385 & 0.0368 \\
\hline $\mathbf{R 2}$ & 0.0013 & 0.0025 & 0.0036 & 0.0043 & 0.0048 & 0.0057 & 0.0015 & 0.0000 & 0.0000 & 0.0000 & 0.0146 & 0.0146 & 0.0142 & 0.0114 & 0.0103 & 0.0138 \\
\hline $\mathbf{R 3}$ & 0.0666 & 0.0027 & 0.0040 & 0.0053 & 0.0067 & 0.0080 & 0.0093 & 0.0107 & 0.0120 & 0.0147 & 0.0133 & 0.0240 & 0.0000 & 0.0047 & 0.0060 & 0.0033 \\
\hline R4 & 0.1333 & 0.0053 & 0.0080 & 0.0107 & 0.0133 & 0.0160 & 0.0187 & 0.0213 & 0.0240 & 0.0293 & 0.0267 & 0.0480 & 0.0000 & 0.0093 & 0.0120 & 0.0067 \\
\hline R5 & 0.0007 & 0.0015 & 0.0022 & 0.0029 & 0.0036 & 0.0044 & 0.0051 & 0.0058 & 0.0065 & 0.0059 & 0.0075 & 0.0102 & 0.0103 & 0.0109 & 0.0109 & 0.0103 \\
\hline R6 & 0.0197 & 0.0197 & 0.0000 & 0.0173 & 0.0000 & 0.0000 & 0.0140 & 0.0060 & 0.0000 & 0.0000 & 0.0000 & 0.0000 & 0.0000 & 0.0000 & 0.0000 & 0.0000 \\
\hline \multicolumn{17}{|c|}{ Aggregated risk assessments on disease prevention in distributed forms } \\
\hline $\begin{array}{l}\text { Degrees of } \\
\text { belief }\end{array}$ & 0.0049 & 0.0011 & 0.0008 & 0.0013 & 0.0011 & 0.0012 & 0.0014 & 0.0015 & 0.0015 & 0.0017 & 0.0019 & 0.0026 & 0.0011 & 0.0015 & 0.0015 & 0.0014 \\
\hline Ignorance & \multicolumn{16}{|c|}{0.973} \\
\hline Mim RA & \multicolumn{16}{|c|}{$3.979 \%$} \\
\hline Max RA & \multicolumn{16}{|c|}{$3.983 \%$} \\
\hline AVRA & \multicolumn{16}{|c|}{$3.896 \%$} \\
\hline \multicolumn{17}{|c|}{ Degree of belief in risk effects materialization equals to: $\mathbf{9 9 . 5 1 \%}$} \\
\hline \multicolumn{17}{|c|}{ Degree of belief in risk no effects materialization equals to $\mathbf{0 . 4 9 \%}$} \\
\hline & imul & isk & esSn & t $(1$ & $\mathbf{R A}$ & Max & um & k ass & mer & Max & A); $A$ & erag & $\mathbf{k}$ & Sm & & \\
\hline
\end{tabular}


Table 3: Risk assessment in distributed forms

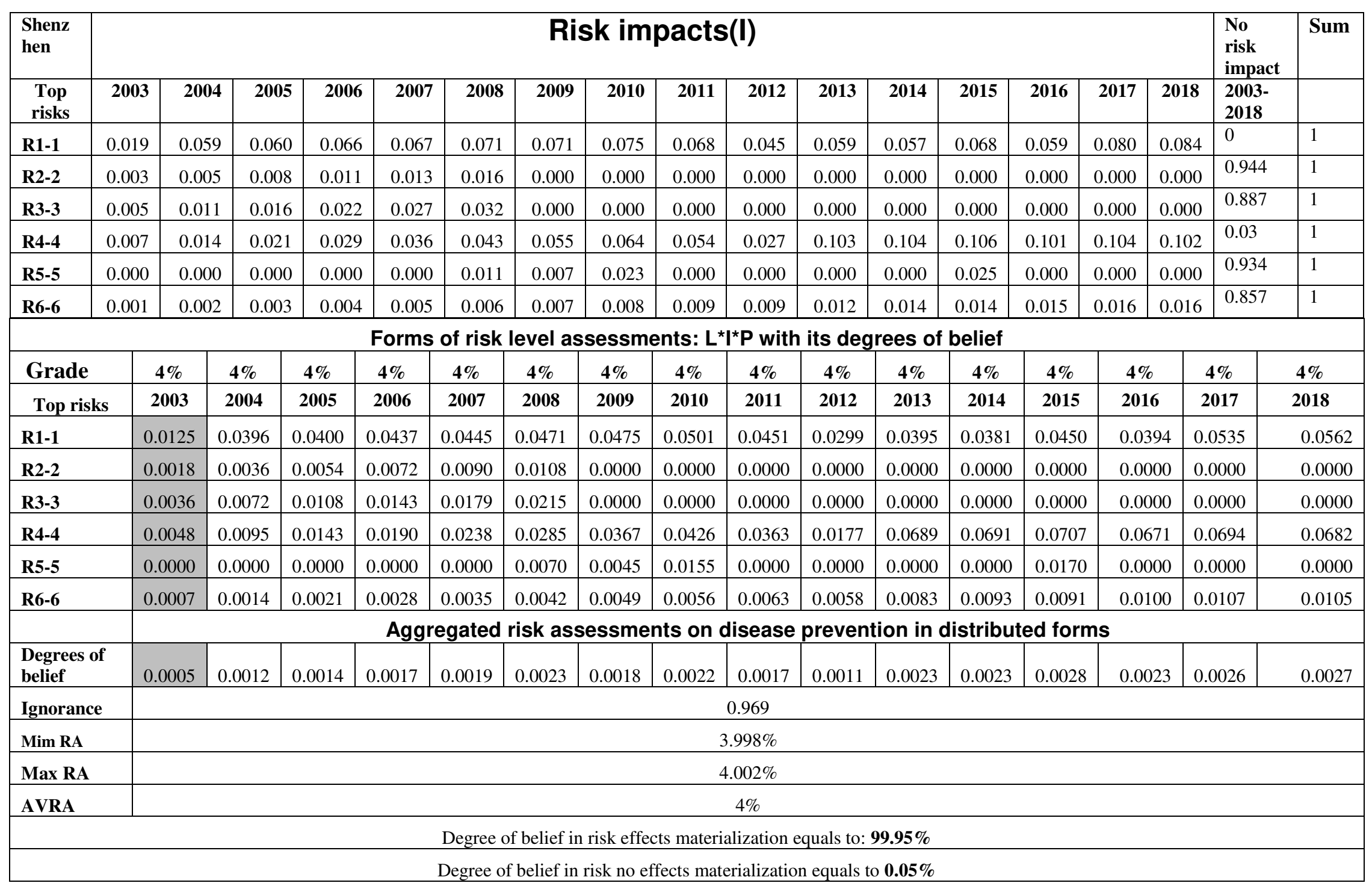


R1=R1-1: Decrease in capability of potential hazards detection

$\mathbf{R 2}=\mathbf{R} 4-4$ : Lack of task performance or increased disease mortality rate

R3=R2-2: Work overload (under stress)

R4=R3-3: Excessive workload (over stress or burnout)

R5=R6-6: Long working hours

R6=R5-5: Delay or reduction of multicomponent interventions 


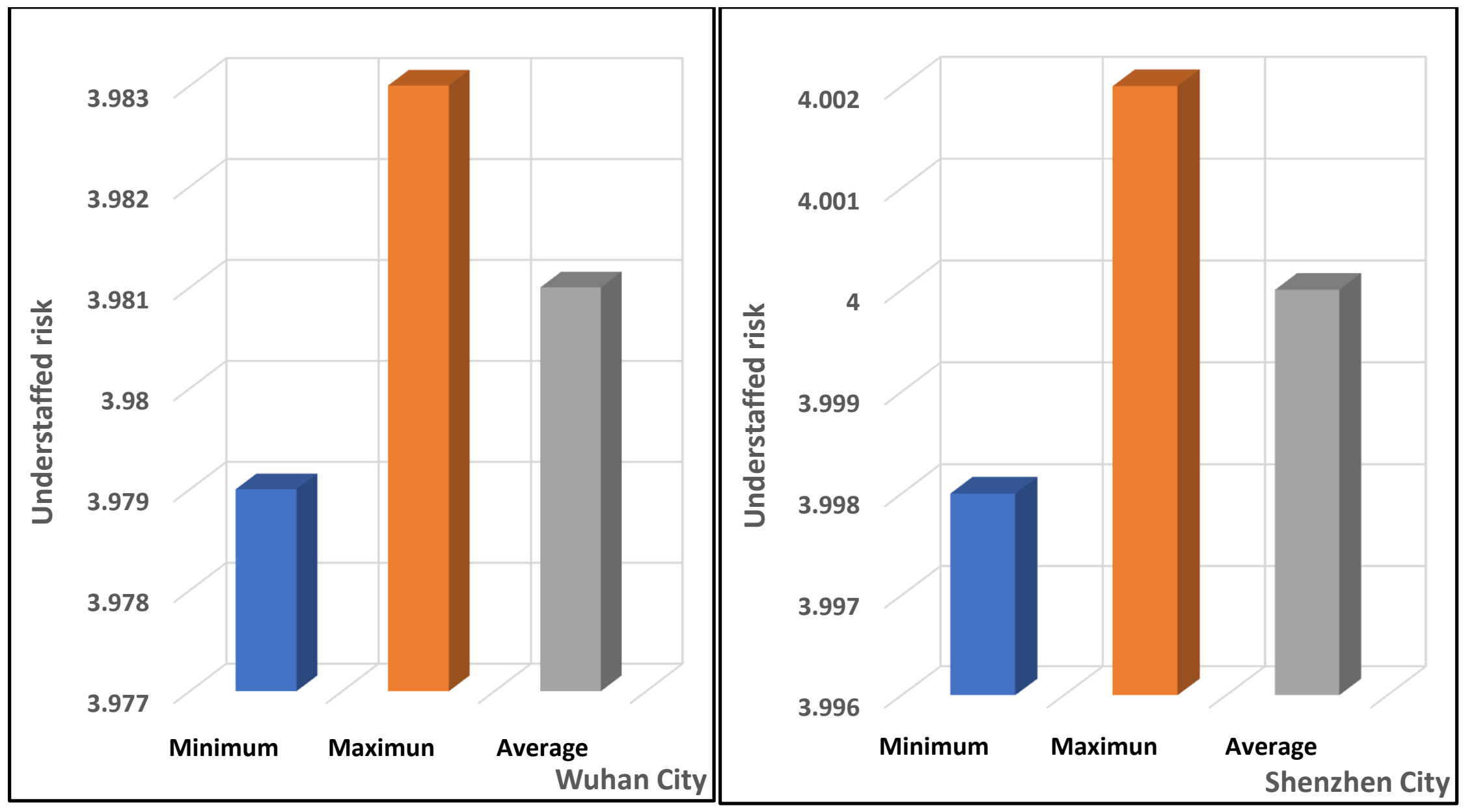

Figure 1: lower, upper, and average risk assessments 


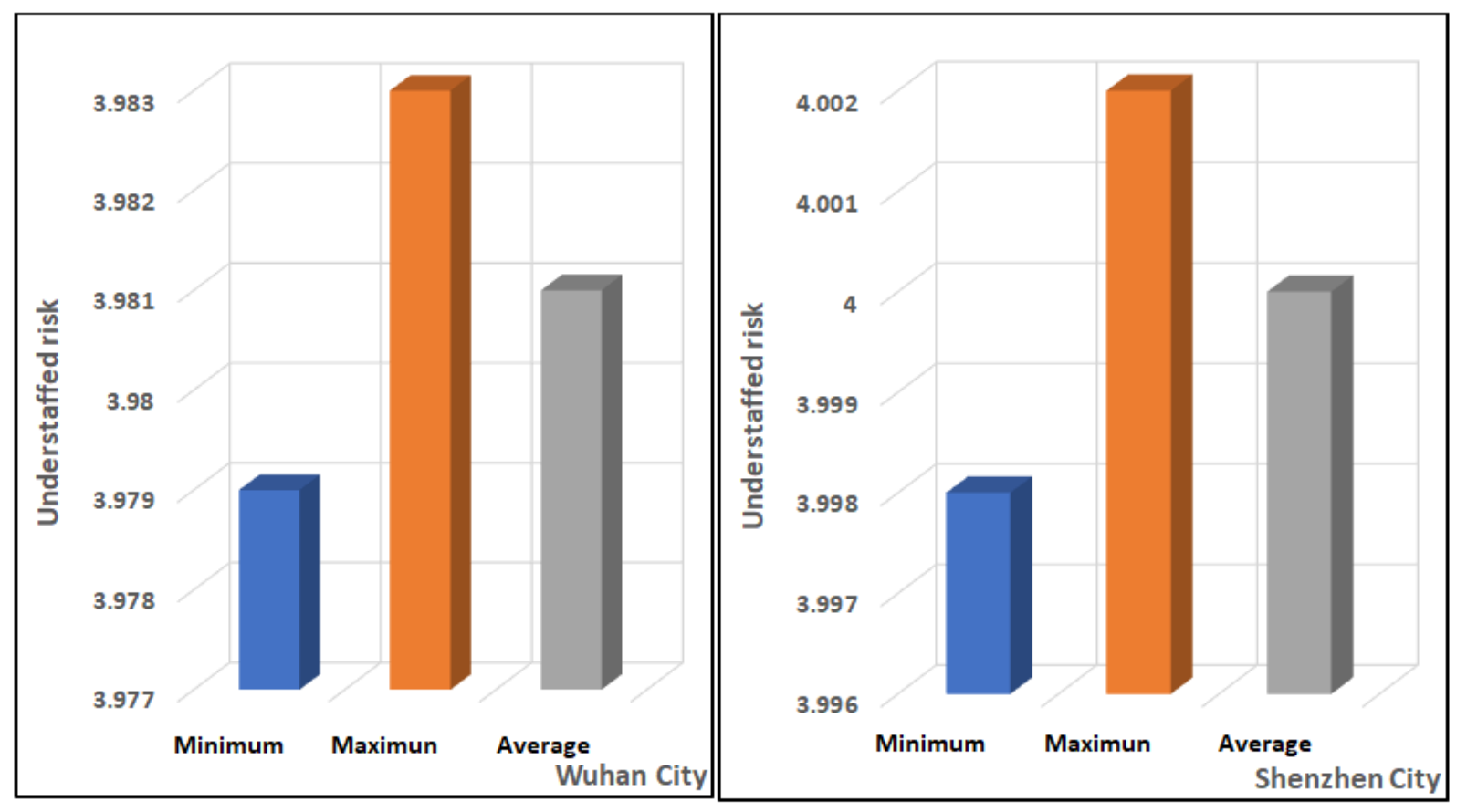




\section{Conclusion and recommendation}

This article studies the understaffed consequences on SARS-CoV-2 outbreak in Wuhan and Shenzhen, which causes population and economic loss. Applying a framework of DST-ER approach, we draw the following main conclusions: first, we show how public health workers, especially workers in disease prevention and control, are under work pressure. Under-work pressure in both cities is mainly due to understaffed workers, which has six (6) factor risks in this study. It includes decrease in ability of potential hazards detection, lack of task performance or increased mortality rate, daily work overload and excessive workload, long working hours and; delay or reduction of multicomponent interventions. Thus, the approximative risks due to understaffed in Wuhan and Shenzhen at the end of 2019 are $0.14 \%$ and $0.27 \%$, respectively. These risk levels contribute to delays in disease prevention or treatment of confirmed SARS-CoV-2 cases in both cities. Moreover, from SARS-CoV-1 to SARS-CoV-2 outbreaks, the results show that Shenzhen city, the epicenter of SARS-CoV-1, is still highly understaffed than Wuhan city, the epicenter of SARS-CoV-2. Meaning that understaffed maximum risk in Shenzhen trails; Wuhan city; by $0.019 \%$ in magnitude. We generally conclude that public health care systems in China, especially in both cities, are at risk and; the Wuhan city SARS-CoV-2 is just the beginning of pandemic of twenty-one century if employment policy in public is not reviewed. Therefore, the SARS CoV-2 outbreak may lead China authorities to rethink public health care employment policy to safeguard workers, patients and prevent future pandemics, respectively. Additionally, this policy may also promote new manufacturing enterprises to strengthen the existence of disease prevention and control machines so that workers can have resort to the technologies of machines to mitigate understaffed effects.

\section{Abbreviation}

R1=R1-1: Decrease in capability of potential hazards detection

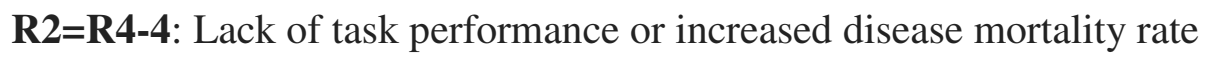

$\mathbf{R 3}=\mathbf{R 2}-2$ : Work overload (under stress)

R4=R3-3: Excessive workload (over stress or burnout)

R5=R6-6: Long working hours

R6=R5-5: Delay or reduction of multicomponent interventions 


\section{References}

1. Yeo, C., Kaushal, S. and Yeo, D. Enteric involvement of coronaviruses: is faecal-oral transmission of SARS-CoV-2 possible. The Lancet Gastroenterology \& Hepatology, 2020; 5(4), pp.335-337 Dol:https://doi.org/10.1016/S2468-1253(20)30048-0

2. Ruiyun Li, Sen Pei, Bin Chen, Yimeng Song, Tao Zhang, Wan Yang, Jeffrey Shaman. Substantial undocumented infection facilitates the rapid dissemination of novel coronavirus (SARS-CoV2),2020 doi: 10.1126/science.abb3221 (2020)

3. Hemida MG. Middle East Respiratory Syndrome Coronavirus and the One Health concept. PeerJ 7: 2019; e7556 https://doi.org/10.7717/peerj.7556

4. Zhu N, Zhang D, Wang W, et al. A novel coronavirus from patients with pneumonia in China, 2019. N Engl J Med 2020; published online Jan 24. DOI:10.1056/NEJMoa2001017.

5. Liu, Q., Luo, D., Haase, J. E., Guo, Q., Wang, X. Q., Liu, S., .. \& Y Yang, B. X. The experiences of health-care providers during the COVID-19 crisis in China: a qualitative study. The Lancet Global Health,2020. https://doi.org/10.1016/S2214-109X(20)30204-7

6. Sadeghniiat-Haghighi, K., \& Yazdi, Z. Fatigue management in the workplace. Industrial psychiatry journal,2015; 24(1), 12.doi: $\underline{\text { 10.4103/0972-6748.160915 }}$

7. Tei-Tominaga, M., \& Nakanishi, M.The influence of supportive and ethical work environments on work-related accidents, injuries, and serious psychological distress among hospital nurses. International journal of environmental research and public health,2018; 15(2), 240. doi:10.3390/ijerph15020240

8. Nogueira, L. S., Domingues, C. A., Poggetti, R. S., \& Sousa, R. M. C. Nursing workload in intensive care unit trauma patients: Analysis of associated factors. PLoS ONE,2014; 9, e112125. https://doi.org/10.1371/ journal.pone. 0112125

9. Bagcchi S. Cholera in Iraq strains the fragile state. Lancet Infect Dis. 2016;16:24-25

10. Burns A, Mensbrugghe D Van der, Timmer H. "Evaluating the Economic Consequences of Avian Influenza.” Working Paper 2006; 47417, World Bank, Washington, DC.

11. Madhav, Nita, Ben Oppenheim, Mark Gallivan, Prime Mulembakani, Edward Rubin, and Nathan Wolfe. "Pandemics: risks, impacts, and mitigation." 2017.

12. Kruuner A, Danilovitsh M, Pehme L, Laisaar T, Hoffner SE, Katila ML. Tuberculosis as an occupational hazard for workers in Estonia. The international journal of tuberculosis 
and lung disease: the official journal of the International Union against Tuberculosis and Lung Disease. 2001;5:170-6.

13. Rosello A, Mossoko M, Flasche S, Hoek A J Van, Mbala P., and others. "Ebola Virus Disease in the Democratic Republic of the Congo, 1976-2015." eLife 2015 (4): e09015.

14. Keeley, Alexander J., Cariad Evans, Hayley Colton, Michael Ankcorn, Alison Cope, Tracy Bennett, Prosenjit Giri, Thushan I. de Silva, and Mohammad Raza. "Roll-out of SARS-CoV-2 testing for healthcare workers at a large NHS Foundation Trust in the United Kingdom, March 2020." Eurosurveillance 25, no. 14 (2020): 2000433.

15. Evans D K, Goldstein M, Popova A. "Health-Care Worker Mortality and the Legacy of the Ebola Epidemic.” The Lancet Global Health 2015; 3 (8): e439-e440.

16. Aiken, L. H., Clarke, S. P., Sloane, D. M., Sochalski, J., \& Silber, J. H. Hospital nurse staffing and patient mortality, nurse burnout, and job dissatisfaction. Jama, 2002; 288(16), 1987-1993. doi:10.1001/jama.288.16.1987

17. Taxis, K., \& Barber, N. Ethnographic study of incidence and severity of intravenous drug errors. Bmj, 2003; 326(7391), 684. doi: https://doi.org/10.1136/bmj.326.7391.684

18. "Medical Errors: An Observational Study." management 4: 5.(2018) DOI$10.21304 / 2018.0503 .00385$

19. DeRigne, LeaAnne, Patricia Stoddard-Dare, and Linda Quinn. "Workers without paid sick leave less likely to take time off for illness or injury compared to those with paid sick leave." Health Affairs 35, no. 3 (2016): 520-

527.HTTPS://DOI.ORG/10.1377/HLTHAFF.2015.0965

20.Eckerman, Ingrid, and Tom Børsen. "Corporate and Governmental Responsibilities for Preventing Chemical Disasters: Lessons from Bhopal." HYLE-International Journal for Philosophy of Chemistry 24 (2018): 29-53.

21. Jansson, M., Ohtonen, P., Syrjälä, H., \& Ala-Kokko, T. The proportion of understaffing and increased nursing workload are associated with multiple organ failure: A crosssectional study. Journal of Advanced Nursing,2020. DOI: 10.1111/jan.14410

22. Carlesi, K. C., Padilha, K. G., Toffoletto, M. C., Henriquez-Roldán, C., \& Juan, M. A. C. Patient safety incidents and nursing workload. Revista latino-americana de enfermagem,2017;25. https://doi.org/10.1590/1518-8345.1280.2841 
23. WHO SARS (2003, Severe Acute Respiratory Syndrome) HTTPS://WWW.WHO.INT/ITH/DISEASES/SARS/EN/

24. Ma, J., W. Zheng, and Z. Pinghui. At least 500 Wuhan medical staff infected with coronavirus. South China Morning Post. February 11, 2020. Available at: https://www.scmp.com/news/china/ society/article/3050077/least-500-wuhan-medicalstaff infected-coronavirus (accessed February 25, 2020).

25. Vincent, C. Understanding and responding to adverse events. N Engl J Med, 2003;348(11), 1051-6.DOI: 10.1056/NEJMHPR020760

26. Volpp, K. G., \& Grande, D.. Residents' suggestions for reducing errors in teaching hospitals. N Engl J Med, 2003;348(9), 851-855.DOI: 10.1056/NEJMSB021667

27. Joseph, J., \& Mohanasundari, S. K.. Incident Report-An Indispensable Pillar in the Health Sector. International Journal of Advances in Nursing Management, 2019; 7(4), 347350.DOI: $10.5958 / 2454-2652.2019 .00081 .7$

28. Fetherston, T. The importance of critical incident reporting-and how to do it. Community eye health, 2015;28(90), 26. https://www.ncbi.nlm.nih.gov/pmc/articles/PMC4675258/pdf/jceh_28_90_026.pdf

29. Kalisch, B. J., Landstrom, G. L., \& Hinshaw, A. S. Missed nursing care: a concept analysis. Journal of advanced nursing, 2009; 65(7), 1509-1517. https://doi.org/10.1111/j.1365-2648.2009.05027

30. Dehghan-Nayeri, N., Ghaffari, F., \& Shali, M. Exploring Iranian nurses' experiences of missed nursing care: a qualitative study: a threat to patient and nurses' health. Medical journal of the Islamic Republic of Iran,2015; 29, 276. https://www.ncbi.nlm.nih.gov/pmc/articles/PMC4715394/\#R8

31. Rassin, M., \& Silner, D. Trends in nursing staff allocation: the nurse-to-patient ratio and skill mix issues in Israel. International nursing review, 2007;54(1), 63-69. https://doi.org/10.1111/j.1466-7657.2007.00529.x

32. Gutsan, Ekaterina, Jami Patton, William K. Willis, and Coustasse Dr PH. "Burnout syndrome and nurse-to-patient ratio in the workplace." (2018).at:https://mds.marshall.edu/mgmt faculty

33. Mani, V., Kesavan, S., \& Swaminthan, J. M. Estimating the impact of understaffing on sales and profitability in retail stores. Production and Operations Management,2015; 24, 
201-218.

DOI: $\underline{10.1111 / \text { poms.12237 }}$

34. Aiken, L. H., Clarke, S. P., Sloane, D. M., Sochalski, J., \& Silber, J. H. Hospital nurse staffing and patient mortality, nurse burnout, and job dissatisfaction. Journal of the American

Medical Association, 2002; 288, 1987-1993

35. Panagioti, M., Geraghty, K., Johnson, J., Zhou, A., Panagopoulou, E., Chew-Graham, C., Peters, D., Hodkinson, A., Riley, R., Esmail, A. Association between Physician Burnout and Patient Safety, Professionalism, and Patient Satisfaction: A Systematic Review and Meta-analysis. JAMA Intern. Med. 2018; 178, 1317-1330. https://doi.org/10.1001/jamainternmed.2018.3713

36. Maunder R, Hunter J, Vincent L, et al. The immediate psychological and occupational impact of the 2003 SARS outbreak in a teaching hospital. CMAJ 2003; 168: 1245-51. https://www.cmaj.ca/content/cmaj/168/10/1245.full.pdf

37. Lee SM, Kang WS, Cho A-R, Kim T, Park JK. Psychological impact of the 2015 MERS outbreak on hospital workers and quarantined hemodialysis patients. Compr Psychiatry 2018; 87: 123-27. https://doi.org/10.1016/j.comppsych.2018.10.003

38. Wu, P., et al. The psychological impact of the SARS epidemic on hospital employees in China: exposure, risk perception, and altruistic acceptance of risk. Canadian journal of psychiatry. Revue canadienne de psychiatrie 2009; 54, 302-311. https://doi.org/10.1192/bjp.194.5.478.

39. Pappa, S., Ntella, V., Giannakas, T., Giannakoulis, V. G., Papoutsi, E., \& Katsaounou, P. Prevalence of depression, anxiety, and insomnia among healthcare workers during the COVID-19 pandemic: A systematic review and meta-analysis. Brain, behavior, and immunity,2020. https://doi.org/10.1016/j.bbi.2020.05.026

40. Oakman, Jodi, Wendy Macdonald, Timothy Bartram, Tessa Keegel, and Natasha Kinsman. "Workplace risk management practices to prevent musculoskeletal and mental health disorders: What are the gaps?." Safety science 101 (2018): 220-230. https://doi.org/10.1016/j.ssci.2017.09.004

41. Kang, L., Ma, S., Chen, M., Yang, J., Wang, Y., Li, R., Yao, L., Bai, H., Cai, Z., Yang, B.X. and $\mathrm{Hu}, \mathrm{S}$. Impact on mental health and perceptions of psychological care among 
medical and nursing staff in Wuhan during the 2019 novel coronavirus disease outbreak: A cross-sectional study,2020. Brain, behavior, and immunity. https://doi.org/10.1016/j.bbi.2020.03.028

42. Carmeli, A., \& Weisberg, J. Exploring turnover intentions among three professional groups of employees. Human Resource Development International, 9(2), 191-206. Carmeli, A., \& Weisberg, J. (2006). Exploring turnover intentions among three professional groups of employees. Human Resource Development International, 9(2), 191-206. https://doi.org/10.1080/13678860600616305

43. Itzick, M., \& Kagan, M. Intention to leave the profession: Welfare social workers compared to health care and community social workers in Israel. Journal of Social Service Research, 2017;43(3), 346-357. http://dx.doi.org/10.1080/01488376.2016.1246402

44. Yang S, Meredith P, Khan A. Stress and burnout among healthcare professionals working in a mental health setting in Singapore. Asian J Psychiatr. 2015;15:15-20. https://doi.org/10.1016/j.ajp.2015.04.005 Epub 2015 Apr 9.

45. Vandenbroeck S, Van Gerven E, De Witte H, Vanhaecht K, Godderis L. Burnout in Belgian physicians and nurses. Occup Med (Lond). 2017;67(7):546-54. https://doi.org/10.1093/occmed/kqx126.

46. Moloney W, Boxall P, Parsons M, Cheung G. Factors predicting registered Nurses' intentions to leave theBmir organization and profession: a job demands-resources framework. J Adv Nurs. 2018;74(4):864-75. https://doi.org/10.1111/jan.13497.

47. Hämmig, O. Explaining burnout and the intention to leave the profession among health professionals - a cross-sectional study in a hospital setting in Switzerland. BMC Health Serv Res 18, 785 (2018). https://doi.org/10.1186/s12913-018-3556-1

48. Manyisa, Zodwa M., and Elsie J. van Aswegen. "Factors affecting working conditions in public hospitals: A literature review." International journal of Africa nursing sciences 6 (2017): 28-38.https://doi.org/10.1016/j.ijans.2017.02.002

49. Tvedt, C., Sjetne, I. S., Helgeland, J., Løwer, H. L., \& Bukholm, G. Nurses' reports of staffing adequacy and surgical site infections: A cross-sectional multi-centre study. International Journal of Nursing Studies,2017; 75, 58-64. http://dx.doi.org/10.1016/j.ijnurstu.2017.07.008 
50. Tomic, W., \& Tomic, E. Existential fulfillment and burnout among principals and teachers. Journal of beliefs \& values,2008; 29(1), 1127.https://doi.org/10.1080/13617670801928191

51. Shafer, G. A mathematical theory of evidence (Vol. 42). Princeton university press, 1976. https://books.google.com.sg/books?hl=en\&lr=\&id=wug9DwAAQBAJ\&oi=fnd\&pg=PR7 $\underline{\& d q}=$ Shafer + G. $+(1976),+$ A + Mathematical + Theory + of + Evidence, + N.J. + Princeton + Unive rsity+Press, + Princeton.\&ots=9RYjVUp4LC\&sig=orDkAW0gqi0fYmz91rHXWtcgVvg\&r edir esc $=\mathrm{y} \# \mathrm{v}=$ onepage $\& \mathrm{q} \& \mathrm{f}=$ false

52. Du, Y. W., \& Zhong, J. J. Group inference method of attribution theory based on Dempster of evidence. Knowledge-Based Systems,2020; 188, 104985. https://doi.org/10.1016/j.knosys.2019.104985

53. Yang, J. B. Rule and utility based evidential reasoning approach for multiattribute decision analysis under uncertainties. European journal of operational research, 2001;131(1), 31-61.

https://personalpages.manchester.ac.uk/staff/jianbo.yang/JB\%20Yang\%20Journal_Papers/ $\underline{\text { RuleUtility.pdf }}$

54. Xu, D. L., \& Yang, J. B. Intelligent decision system based on the evidential reasoning approach and its applications. Journal of Telecommunications and information technology,2005; 73-

80.http://yadda.icm.edu.pl/baztech/element/bwmeta1.element.baztech-article-BAT3-00270009/c/httpwww_itl_waw_plczasopismajtit2005373.pdf

55. Leung, M. Y., Sham, J., \& Chan, Y. S. Adjusting stressors-job-demand stress in preventing rustout/burnout in estimators. Surveying and Built Environment,2007; 18(1), $17-26$.

56. Büssing A, Falkenberg Z, Schoppe C, Recchia DR, Poier D. Work stress associated cool down reactions among nurses and hospital physicians and their relation to burnout symptoms. BMC Health Serv Res. 2017;17(1):551. https://doi.org/10.1186/s12913-017$\underline{2445-3}$.

57. de Oliveira DR, Griep RH, Portela LF, Rotenberg L. Intention to leave profession, psychosocial environment and self-rated health among registered nurses from large hospitals in Brazil: a cross-sectional study. BMC Health Serv Res. 2017;17(1):21. https://doi.org/10.1186/s12913-016-1949-6. 
58. Van Cott H. Human errors: Their causes and reductions. In: Bogner S, editor. Human Error in Medicine. Hillscale, NJ: Erlbaum; 1994 https://psycnet.apa.org/record/1994$\underline{98177-001}$

59. Taroun, A., \& Yang, J. B. Dempster-Shafer theory of evidence: potential usage for decision making and risk analysis in construction project management. The Built \& Human Environment Review,2011. https://uobrep.openrepository.com/bitstream/handle/10547/251021/51-141-1$\underline{\mathrm{PB}(1) . p d f \text { ?sequence }=1}$

\section{Declaration of conflicting interests}

The author(s) declared no potential conflicts of interest with respect to the research, authorship, and/or publication of this article.

\section{Funding}

No funding supports this research.

\section{Availability of data and materials}

Data uses in this research are publicly available and, attached in this manuscript.

\section{Authors' contributions}

Authors contribute equally to this manuscript.

\section{Authors' information}

Wadjidou BOUKARI, Ph.D. Student in Science and Engineering Management

Dr. Ivana Todorovic, Scholar in public health care, Tsinghua University, Research center of public health

Fenjie Long. Professor, Dept. of Civil Engineering, Tsinghua University, West mainly building (floor N0.406), Beijing City, China. 


\section{Appendix}

In a hierarchy of two levels, the aggregation of the distributed assessments of 1 criteria is conducted according to the following steps:

1- Assign importance weights $\omega_{i}(i=1, \ldots, l)$ to decision criteria. The weights must be normalized, so that $0 \leq \omega_{i} \leq 1$ and $\sum_{i}^{l} \omega_{i}=1$.

2- Transform the degrees of belief into basic probability assignments by multiplying them with the importance weights:

$m_{n, i}=m_{i}\left(H_{n}\right)=\beta_{n, i}\left(A_{m}\right) \quad n=1, \ldots, N \quad i=1, \ldots, l$.

$m_{n, i}$ Represents the probability mass assigned to the evaluation grade $H_{n}$ when considering the criterion $C_{i}, \mathrm{~N}$ is the number of assessment grades

3- Calculate the probability mass assigned to the whole frame of discernment (a set of $\mathrm{N}$ evaluation grades) on every criterion by:

$m_{H, i}=m_{i}(H)=1-\sum_{n=1}^{N} m_{n, i} \quad i=1, \ldots, l$.

This probability mass can be split into two parts:

$\bar{m} H, i=1-\omega_{i}$ caused by the weight of the criterion $C_{i}$ and $\tilde{m} H, i=\omega i *\left(1-\sum_{n=1}^{N} \beta_{n, i}(A i)\right), \quad i=1, \ldots, l$

4- Aggregate the probability assignments by means of the following equations:

$$
\begin{gathered}
\left.m_{n}=k *\left[\prod_{i=1}^{l}\left(m_{n, i}+\bar{m} H, i+\widetilde{m} H, i\right)-\prod_{i=1}^{i} \bar{m} H, i+\widetilde{m} H, i\right)\right], n=1, \ldots, N \\
k=\left[\sum_{n=1}^{N} \prod_{i=1}^{l}\left(m_{n, i}+\bar{m} H, i+\widetilde{m} H, i\right)-(N-1) * \prod_{i=1}^{l}(\bar{m} H, i+\widetilde{m} H, i)\right]^{-1}
\end{gathered}
$$

5- Aggregate the probability masses assigned to the whole frame of discernment:

$$
\begin{aligned}
& \tilde{m} H=k *\left[\prod_{i}^{l}(\bar{m} H, i+\widetilde{m} H, i)-\prod_{i=1}^{l}(\bar{m} H, i)\right] \\
& \bar{m} H=k *\left[\prod_{i=1}^{l}(\bar{m} H, i)\right]
\end{aligned}
$$

6- Transform the aggregated probability masses into an aggregated belief structure in the shape of $S\left(C_{j}(A)\right)=\left(H_{n}, \beta_{n, i}\left(A_{i}\right)\right.$.Such a transformation requires calculating the belief degrees $\beta_{n}(n=1, \ldots, N)$ using the following equation: 


$$
\beta_{n}=\frac{m_{n}}{1-\bar{m} H}, n=1, \ldots, N
$$

7- Calculate the aggregated degree of ignorance $\beta_{H}$ :

$$
\beta_{H}=\frac{\widetilde{m}_{n}}{1-\bar{m} H}=1-\sum_{i=1}^{N} \beta_{n}, n=1, \ldots, N
$$

The aggregation result is an overall belief structure. In this belief structure, the overall degrees of belief $\beta_{H}$ together with the degree of ignorance $\beta_{n}$ always sum to unity which is perfectly logical.

In order to compare between different alternatives, the overall assessment should be transformed from its distributed form into a representative score. Yang (2001) proposed calculating an expected utility for every alternative $u\left(S\left(A_{j}\right)\right)$ as follows:

$$
u\left(S\left(A_{j}\right)\right)=\sum_{n=1}^{N} u\left(H_{n}\right) * \beta_{n} \quad n=1, \ldots, N
$$

By agreeing upon utility values for every evaluation grade, an expected utility value for every alternative can be estimated. In the case of incomplete assessment, the degree of ignorance can be utilized in order to generate a utility interval with upper and lower levels (Yang 2001) as follows:

$$
\begin{aligned}
& u_{\min }\left(A_{j}\right)=\left(\beta_{1}+\beta_{H}\right) * u\left(H_{1}\right)+\sum_{n=2}^{N} \beta_{n} * u\left(H_{n}\right) \\
& u_{\max }\left(A_{j}\right)=\sum_{n=1}^{N-1} \beta_{n} * u\left(H_{n}\right)+\left(\beta_{N}+\beta_{H}\right) * u\left(H_{n}\right)
\end{aligned}
$$

$H_{1}$ is the assessment grade with the lowest utility value and $H_{n}$ is the assessment grade with the maximum utility value. $u_{\min }$ and $u_{\max }$ can be easily averaged in order to rank the alternatives according to their average utility level.

According to Yang and $\mathrm{Xu}$ (2005), the ER aggregation algorithm is a rational way of aggregating information that satisfies the following axioms:

-If no sub-criterion is assessed to an evaluation grade, the general criterion should not be assessed to the same grade either.

-If all sub-criteria are precisely assessed to a specific grade, the general criterion should also be precisely assessed to the same grade.

-If all sub-criteria are completely assessed to a subset of the evaluation grades, the general criterion should be completely assessed to the same subset as well. 
-If any assessment of a sub-criterion is incomplete, the assessment of the general criterion should also be incomplete. 
Figures

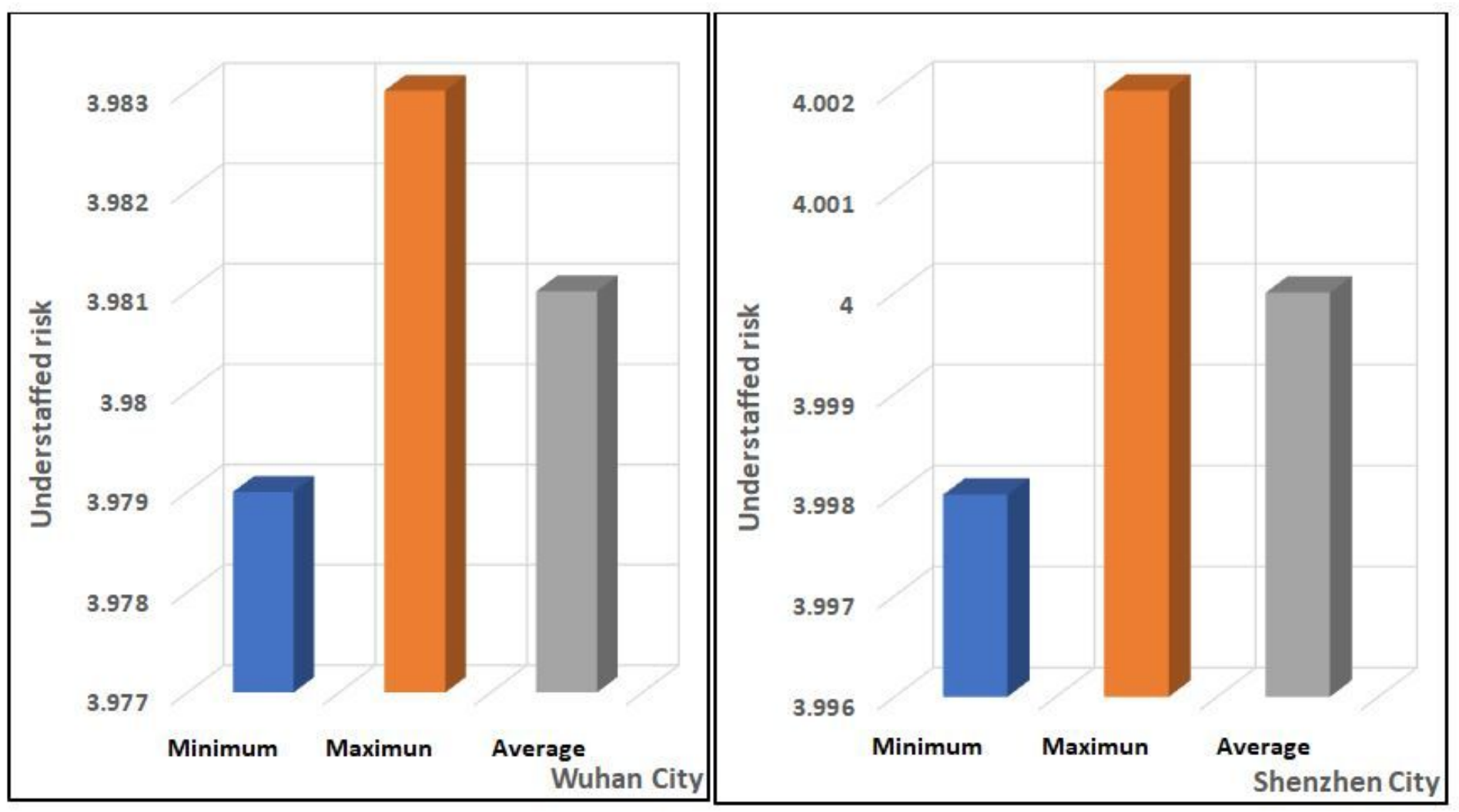

Figure 1

lower, upper, and average risk assessments

\section{Supplementary Files}

This is a list of supplementary files associated with this preprint. Click to download.

- DATASETS.xls

- ESTIMATIONDETAILS.docx 